\section{Situación de salud post pandemia}

\section{Post pandemic health situation}

\section{Señor Editor,}

Chile y el mundo transitaron rápidamente desde enfermedades infecciosas y materno infantiles en la década del 70, a un predominio de las enfermedades crónicas no transmisibles y problemas de salud mental a partir de la década del 90 en adelante ${ }^{1,2}$.

En los últimos 10 años se han producido cambios importantes en Chile con envejecimiento de la población y aumento de las muertes por cáncer, desplazando a las cardiovasculares como primera causa de muerte, siendo el segundo país en América del Sur después de Uruguay $^{3}$. Sin embargo, hubo atisbos de que las enfermedades infecciosas podrían reaparecer, como fue el caso del cólera en 1990, la epidemia de influenza el 2009 y la aparición de nuevos virus como el ébola, la gripe aviar y otros.

Con la pandemia del coronavirus, la situación epidemiológica y las principales causas de muerte van a cambiar desde el año 2020 en adelante. La transición epidemiológica y nutricional depende de los cambios demográficos y socioeconómicos. En demografía, los nacimientos han disminuido y la alta mortalidad por coronavirus hacen prever cambios demográficos y una disminución de la expectativa de vida en muchos países.

En epidemiología, lo más probable es que por mucho tiempo las enfermedades crónicas y degenerativas convivan con el COVID-19, sus mutaciones y la posibilidad de que aparezcan nuevos virus y epidemias. El confinamiento prolongado ha incrementado los problemas de salud mental ${ }^{4}$. La rehabilitación física y emocional de pacientes hospitalizados es un problema mayor, especialmente de aquellos que estuvieron con ventilación mecánica invasiva por largo tiempo. A esto se agrega la postergación en la atención de las actuales enfermedades como cáncer, cardiovasculares, diabetes y otras, que al no haber sido controladas en forma oportuna hacen prever un incremento en su prevalencia y gravedad.

En los cambios nutricionales, la situación no es mejor. La pandemia ha llevado a la inseguridad alimentaria de los sectores más vulnerables. Esta inseguridad alimentaria produce dificultad de acceso físico y económico a alimentos más sanos, especialmente frutas y verduras, legumbres, pescado, lácteos y las personas optan por consumir una alta cantidad de alimentos ultraprocesados, farináceos y frituras de bajo costo, lo que junto a la inactividad física producto de las cuarentenas, llevará a un incremento de la obesidad, especialmente en niños y adolescentes, como ya se observó en el Mapa Nutricional de la JUNAEB $2020^{5}$.
En consecuencia, nos encontramos frente a cambios demográficos, epidemiológicos y nutricionales importantes. De una situación de pre transición epidemiológica y nutricional en los 70, pasamos a una post transición a fines de los 80 y a una cuarta fase de la transición epidemiológica ${ }^{6}$ del 2000 en adelante, con una población muy envejecida aumento del cáncer, demencias y enfermedades degenerativas.

Ante esta situación, debemos anticiparnos a los cambios epidemiológicos y estar preparados para enfrentar en forma adecuada la compleja situación sanitaria post pandemia que se nos avecina, para que no sobrepase nuestra capacidad como país afectando nuestro desarrollo.

Para ello debemos adecuar nuestras políticas públicas y seguir fortaleciendo el sistema de salud público y privado, aumentando la proporción del gasto en salud del PIB, con mayor infraestructura, más y mejor formación del recurso humano, y especialmente realizando acciones de promoción y prevención de salud.

Fernando Vio del Río ${ }^{1,2}$

${ }^{1}$ Profesor Titular INTA Universidad de Chile. ${ }^{2}$ Presidente de la Corporación 5 al día Chile.

\section{Referencias}

1. Albala C, Vio F, Yáñez M. Transición Epidemiológica en América Latina: Comparación de cuatro países. Rev Med Chile 1997; 125: 719-27.

2. Vio F, Albala C, Kain J. Nutrition transition in Chile revisited: mid-term evaluation of obesity goals for the period 2000-2010. Public Health Nutr 2008; 11: 405-12.

3. Martínez-Sanguinetti A, Leiva-Ordoñez AM, Petermann-Rocha F, Celis-Morales C. ¿Cómo ha cambiado el perfil epidemiológico en Chile en los últimos 10 años? (Carta al Editor). Rev Med Chile 2021; 149: 149-52.

4. Brooks SK Webster RK Smith LE et al. The psychological impact of the quarentine and how to reduce it: rapid review of the evidence. Lancet 2020; 395: 912-20.

5. Mapa Nutricional JUNAEB 2020. Disponible en: https:// www.sochob.cl/web1/wp-content/uploads/2021/03/Mapa-Nutricional-JUNAEB-2020-1.pdf [Consultado el 27 de mayo de 2021].

6. Olshansky SJ, Ault B. The Fourth Stage of the Epidemiologic Transition: The Age of Delayed Degenerative Diseases. The Milbank Quarterly 1986; 64: 355-91.

Correspondencia a:

Dr. Fernando Vio del Río

Instituto de Nutrición y Tecnología de los Alimentos Universidad de Chile.

El Líbano 5524, Macul. Santiago, Chile.

fvio@inta.uchile.cl 